\title{
Metacognitive mastery in persons with first-episode psychosis and their caregivers: Implications for timely help-seeking and caregiver experiences. Brief report.
}

Jens Einar Jansen ${ }^{\mathrm{a}}$, Paul H Lysaker ${ }^{\mathrm{b}, \mathrm{c}}$, Anne Marie Trauelsen ${ }^{\mathrm{a}}$, Lauren Luther ${ }^{\mathrm{d}}$, Ulrik Helt Haahr $^{\mathrm{a}}$, Hanne-Grethe Lyse ${ }^{\mathrm{e}}$, Marlene Buch Pedersen ${ }^{\mathrm{e}}$, Erik Simonsen ${ }^{\mathrm{a}, \mathrm{f}, \mathrm{g}}$

${ }^{\mathrm{a} P s y c h i a t r i c ~ R e s e a r c h ~ U n i t, ~ P s y c h i a t r y ~ R e g i o n ~ Z e a l a n d, ~ S l a g e l s e, ~ D e n m a r k ~}$

${ }^{\mathrm{b}}$ Roudebush VA Medical Center, Indianapolis, Indiana, USA

${ }^{\mathrm{c}}$ Department of Psychiatry, Indiana University School of Medicine, Indianapolis, USA

${ }^{\mathrm{d}}$ Indiana University-Purdue University Indianapolis, Indiana, USA

${ }^{\mathrm{e}}$ Early Psychosis Intervention Center, Psychiatry East Region Zealand, Roskilde, Denmark

${ }^{\mathrm{f}}$ Faculty of Health and Medical Sciences, University of Copenhagen, Denmark

${ }^{\mathrm{g}}$ Institute of Clinical Medicine, University of Copenhagen, Denmark

\begin{abstract}
While metacognitive mastery seems to be closely linked to general functioning in persons with psychosis, little is known of metacognitive capacity of family members, who often play an important role in recovery and often report high levels of distress. We gathered assessments of metacognitive mastery from persons with first-episode psychosis and their mothers. We found that relatively higher overall mean mastery levels among the dyads, was related to negative caregiver experiences, and caregiver critical comments. Greater levels of mastery were related to decreased duration of untreated psychosis. Clinical implications in terms of family intervention programmes repertoire are discussed.
\end{abstract}

\section{Introduction}

Metacognition refers to the range of mental activities that allow people to both recognize specific thoughts and feelings and to integrate perceptions of intentions, thoughts, feelings, and connections between events into larger complex representations (Lysaker et al., 2015; Semerari et al., 2003). Metacognition deficits have been observed in persons in early and later phases of

This is the author's manuscript of the article published in final edited form as:

Jansen, J. E., Lysaker, P. H., Trauelsen, A. M., Luther, L., Haahr, U. H., Lyse, H.-G., ... Simonsen, E. (2017).

Metacognitive mastery in persons with first-episode psychosis and their caregivers: Implications for timely help-seeking and caregiver experiences. Brief report. Psychiatry Research. https://doi.org/10.1016/j.psychres.2017.02.003 
schizophrenia-spectrum disorders and linked to poorer outcomes (Trauelsen et al., 2016). One form of metacognitive capacity metacognitive mastery, or the ability to use metacognitive knowledge to respond to psychosocial challenges (Carcione et al., 2011) has been closely linked to outcomes including passive coping, social anxiety (Lysaker et al., 2011), social withdrawal (Lysaker et al., 2010) and general inactivity (Snethen et al., 2014).

One limitation of this literature is that it has considered the metacognitive capacities of patients independent of the metacognitive capacity of family members who often play a major role in any movements towards well-being, especially early in the course of illness. Only one study has examined metacognition in caregivers, finding that caregivers of persons with first episode psychosis (FEP) with greater levels of metacognition reported higher levels of positive caregiver experiences (Jansen et al., 2014b). Understanding the role of mastery if FEP seems especially important given needs to intervene and prevent prolonged dysfunction.

To explore this issue, the current study gathered assessments of metacognitive mastery from persons with FEP and mothers in cases where the two were living together. Given the increased emotional, physical, and fiscal challenges of being a parent of a child with FEP living at home (Lowyck et al., 2004; Sin et al., 2007), especially during the early course of psychosis, we focused on biological maternal caregivers living with their child in a FEP. Further, mothers were of specific interest given that they often report increased distress (Tennakoon et al., 2000) and are generally the primary caregiver (Cotton et al., 2013; Jansen et al., 2015a; Onwumere et al., 2011; Scazufca and Kuipers, 1997) of a person experiencing psychosis. We then examined whether the level of metacognitive mastery in patients and/or their caregivers was related to the quality of the caregiving relationship and how long the patient initially waited after the onset of illness to seek treatment. Mastery was chosen because if it is difficult for a caregiver to identify and synthetize their own mental states and the mental states of others, including their child, it could be difficult to cope with challenges and distress associated with caregiving. Further, with limited understanding of one's mental states, it could be difficult to not only identify psychological challenges their child is facing but also to respond to their child and their needs in an adaptive way.

\subsection{Hypotheses and exploratory questions}

Our primary hypothesis was that greater metacognitive mastery among FEP patients and maternal caregivers would predict decreased duration of untreated psychosis, greater positive and less negative caregiver experiences, and decreased caregiver critical comments and emotional overinvolvement. In addition, reasoned that both overall mean level of mastery as well as the overall differences in levels of mastery of the dyad were uniquely related to outcomes. Here we formed two complementary hypotheses; first that higher overall levels of mastery would predict better outcomes and second, that at a more nuanced level, more concordant levels of mastery would predict better outcomes. Regarding the later hypotheses, we reasoned that more discordant levels of mastery could result in greater levels of misunderstanding, resulting in poor care giving relationships.

\section{Methods}

\subsection{Participants}


Participants included 19 men and 9 women with FEP (ICD-10 F20-29, except F21) and their maternal caregiver drawn from a larger study examining caregiver distress and family interventions. Detailed information on sample selection has been presented elsewhere (Jansen et al., 2015b). Patients were a mean age of 20.01 ( $S D=3.03)$, and had a mild to moderate levels of positive and negative symptoms. Mothers had a mean age of $48.33(\mathrm{SD}=5.00)$.

\subsection{Measures}

Duration of untreated psychosis (DUP) was defined as Positive and Negative Syndrome Scale for Schizophrenia (PANSS; Kay et al., 1987), psychotic symptom score of $\geq 4$ either constantly for a week or several times a week for several weeks (Melle et al., 2006). Metacognitive mastery in patients and caregivers were assessed by the Indiana Psychiatric Illness Interview (IPII; Lysaker et al., 2002) and the Metacognition Assessment Scale - abbreviated (MAS-A; Lysaker et al., 2005; Semerari et al., 2003). Experience of caregiving was assessed with the 66-item the Experience of Caregiving Inventory (ECI; Szmukler et al., 1996). Expressed emotion was assessed with the 20-item Family Questionnaire (Wiedemann et al., 2002). Negative and positive symptoms were assessed with the PANSS, using a factor structure from Bell et al. (1994). Description and psychometric properties of the measures, including the Danish MAS-A, are described elsewhere (Jansen et al., 2015b, 2014a; Trauelsen et al., 2016).

\subsection{Procedure}

Patients and their caregivers were approached for participation when they entered treatment. Following informed written consent, questionnaires and semi-structured interviews were administered. The Regional Committee for Research Ethics approved the study (reg.nr. 2008580020).

\subsection{Analyses}

First, the average and absolute difference mastery score for each mother and patient dyad was calculated. Given that metacognitive mastery and negative symptoms were significantly correlated in the larger patient sample used in this study (Trauelsen et al., 2016) as well as in previous studies (Lysaker et al., 2005), we used negative symptoms as a covariate in the remaining analyses. To test our primary hypothesis, we conducted partial correlations between both maternal and patient mastery scores and duration of untreated psychosis, positive and negative caregiver experiences, and caregiver critical comments and emotional overinvolvement controlling for negative symptoms Additional hypotheses were tested by calculating partial correlations between both the average dyad mastery score and the absolute difference dyad mastery score and the abovementioned measures controlling for negative symptoms. Based on directional a priori hypotheses, all correlations were one-tailed.

\section{Results}

Descriptive statistics for study measures are in Table 1. Mean patient mastery scores suggest at best an ability to seek support when facing psychosocial challenges while mothers were able to alter behavior and cognitions when facing psychosocial challenges. Controlling for negative symptoms, maternal mastery was significantly associated with patient mastery $(r=0.36, p=$ 0.03). Additional partial correlations are in Table 2. After controlling for patient symptoms, 
increased patient mastery was significantly associated with decreased negative caregiver experiences $(p=0.002)$ and caregiver critical comments $(p=0.009)$. Increased maternal mastery was significantly associated with decreased duration of untreated psychosis $(p=0.02)$ and caregiver critical comments $(p=0.048)$ after controlling for negative symptoms. Increased average dyad mastery scores were significantly associated with decreased duration of untreated psychosis $(p=0.047)$, negative caregiver experiences $(p=0.01)$, and caregiver critical comments $(p=0.009)$ independent of negative symptoms. Finally, increased absolute differences in dyad mastery scores were significantly associated with greater caregiver emotional overinvolvement $(p=0.02)$ after controlling for negative symptoms.

\section{Discussion}

This study examined whether levels of metacognitive mastery, in persons with FEP and their mothers were related to the quality of the caregiving relationship and how long the patient initially waited after their illness onset to seek treatment. We also examined whether the overall mean mastery or differences in mastery of the dyad were uniquely related to some outcomes.

We found that relatively higher overall mean mastery levels among the dyads were related to negative caregiver experiences and caregiver critical comments. We also found dyads in which mother's capacity were relatively greater than their adult children there was greater report of overinvolvement. Concerning treatment history, greater levels of mastery were related to decreased DUP. These findings persisted when symptom severity was controlled.

While the correlational nature of the study precludes drawing causal conclusions, results suggest several hypotheses for future research. First, it may be that levels of metacognitive mastery in both maternal caregivers and their children protect against negative experiences and criticism in caregiving relationships. This may be of importance, since criticism is considered a robust predictor of relapse and symptom exacerbation in persons with psychosis as well as other mental disorders (Alvarez-Jimenez et al., 2012; Butzlaff and Hooley, 1998; Wearden et al., 2000). It is also possible that greater mastery levels among mothers helps the mother and adult child enter treatment sooner, rather than waiting for even greater crises. A final speculation is that when there is greater discord between a caregiver and their child's ability to use knowledge of mental states of oneself and others to cope with problems and challenges, the caregiver may become overprotective or intrusive as a means to try to support or develop their child's ability to cope with their illness. This would be consistent with Meins et al.'s (2002) work on maternal mindmindedness. Of note, rival hypotheses cannot be ruled out and these interpretations should be taken as areas for future research.

There are limitations. We examined only adult child-mother dyads. More research is needed to understand whether the same pattern occurs in fathers or between two partners and their children. Although analyses controlled for negative symptoms, other factors likely play a role in predicting the relatives' distress and duration of untreated psychosis. Third, our participants were White Danish adults; we do not know to whether the findings generalize to other ethnic groups. Moreover, recruiting dyads may have imposed limitations on who was nominated to take part and may restrict the representativeness of the sample. Future longitudinal study is needed with more diverse groups. 
With replication, these results have clinical implications. First, targeting metacognition in early intervention family services may help to reduce DUP. Second, metacognitive interventions, which have been found to be acceptable to first episode patients, even when in denial of illness (Hillis et al., 2015; Leonhardt et al., 2016), could be tailored for families and be used to broaden the intervention repertoire within FEP services. These treatments may assist caregivers and adults with FEP to evolve and use more complex ideas about themselves and others to manage psychosocial challenges leading to more fulfilling family relationships. Strengthening family relationships may then synergistically promote the process of recovery and relieve the burden of care for family members.

\section{References}

Alvarez-Jimenez, M., Priede, A., Hetrick, S.E., Bendall, S., Killackey, E., Parker, A.G., McGorry, P.D., Gleeson, J.F., 2012. Risk factors for relapse following treatment for first episode psychosis: a systematic review and meta-analysis of longitudinal studies. Schizophr. Res. 139, 116-28. doi:10.1016/j.schres.2012.05.007

Bell, M.D., Lysaker, P.H., Beam-Goulet, J.L., Milstein, R.M., Lindenmayer, J.-P., 1994. Fivecomponent model of schizophrenia: Assessing the factorial invariance of the positive and negative syndrome scale. Psychiatry Res. 52, 295-303. doi:10.1016/0165-1781(94)90075-2

Butzlaff, R.L., Hooley, J.M., 1998. Expressed emotion and psychiatric relapse: a meta-analysis. Arch. Gen. Psychiatry 55, 547-52. doi:10.1001/archpsyc.55.6.547.

Carcione, A., Nicolò, G., Pedone, R., Popolo, R., Conti, L., Fiore, D., Procacci, M., Semerari, A., Dimaggio, G., 2011. Metacognitive mastery dysfunctions in personality disorder psychotherapy. Psychiatry Res. 190, 60-71. doi:10.1016/j.psychres.2010.12.032

Cotton, S.M.M., McCann, T.V. V, Gleeson, J.F.F., Crisp, K., Murphy, B.P.P., Lubman, D.I.I., 2013. Coping strategies in carers of young people with a first episode of psychosis. Schizophr. Res. 146, 118-124. doi:10.1016/j.schres.2013.02.008

Hillis, J.D., Leonhardt, B.L., Vohs, J.L., Buck, K.D., Salvatore, G., Popolo, R., Dimaggio, G., Lysaker, P.H., 2015. Metacognitive reflective and insight therapy for people in early phase of a schizophrenia spectrum disorder. J. Clin. Psychol. 71, 125-135. doi:10.1002/jclp.22148

Jansen, J.E., Gleeson, J., Cotton, S., 2015a. Towards a better understanding of caregiver distress in early psychosis: A systematic review of the psychological factors involved. Clin. Psychol. Rev. 35, 56-66. doi:10.1016/j.cpr.2014.12.002

Jansen, J.E., Haahr, U.H., Harder, S., Trauelsen, A.M., Lyse, H., Pedersen, M.B., Simonsen, E., 2015b. Caregiver distress in first-episode psychosis: the role of subjective appraisal, overinvolvement and symptomatology. Soc. Psychiatry Psychiatr. Epidemiol. 50, 371-378. doi:10.1007/s00127-014-0935-8

Jansen, J.E., Lysaker, P.H., Harder, S., Haahr, U.H., Lyse, H.-G., Pedersen, M.B., Trauelsen, A.M., Simonsen, E., 2014a. Positive and negative caregiver experiences in first-episode psychosis: emotional overinvolvement, wellbeing and metacognition. Psychol. Psychother. 87, 298-310. doi:10.1111/papt.12014

Jansen, J.E., Lysaker, P.H., Harder, S., Haahr, U.H., Lyse, H.G., Pedersen, M.B., Trauelsen, A.M., Simonsen, E., 2014b. Positive and negative caregiver experiences in first-episode psychosis: Emotional overinvolvement, wellbeing and metacognition. [References]. Psychol. Psychother. Theory, Res. Pract. 298-310.

Kay, S.R., Fiszbein, A., Opler, L.A., 1987. The positive and negative syndrome scale (PANSS) 
for schizophrenia. Schizophr. Bull. 13, 261-76. doi:10.1093/schbul/13.2.261

Leonhardt, B.L., Benson, K., George, S., Buck, K.D., Shaieb, R., Vohs, J.L., 2016. Targeting Insight in First Episode Psychosis: A Case Study of Metacognitive Reflection Insight Therapy (MERIT). J. Contemp. Psychother. 46, 207-216. doi:10.1007/s10879-016-9332-9

Lowyck, B., De Hert, M., Peeters, E., Wampers, M., Gilis, P., Peuskens, J., 2004. A study of the family burden of 150 family members of schizophrenic patients. Eur. Psychiatry 19, 395401. doi:10.1016/j.eurpsy.2004.04.006

Lysaker, P.H., Carcione, A., Dimaggio, G., Johannesen, J.K., Nicolo, G., Procacci, M., Semerari, A., 2005. Metacognition amidst narratives of self and illness in schizophrenia: associations with neurocognition, symptoms, insight and quality of life. Acta Psychiatr. Scand. 112, 6471. doi:10.1111/j.1600-0447.2005.00514.x

Lysaker, P.H., Clements, C.A., Plascak-Hallberg, C.D., Knipscheer, S.J., Wright, D.E., 2002. Insight and Personal Narratives of Illness in Schizophrenia. Psychiatry Interpers. Biol. Process. 65, 197-206. doi:10.1521/psyc.65.3.197.20174

Lysaker, P.H., Erickson, M., Ringer, J., Buck, K.D., Semerari, A., Carcione, A., Dimaggio, G., 2011. Metacognition in schizophrenia: the relationship of mastery to coping, insight, selfesteem, social anxiety, and various facets of neurocognition. Br. J. Clin. Psychol. 50, 41224. doi:10.1111/j.2044-8260.2010.02003.x

Lysaker, P.H., Shea, A.M., Buck, K.D., Dimaggio, G., Nicolò, G., Procacci, M., Salvatore, G., Rand, K.L., 2010. Metacognition as a mediator of the effects of impairments in neurocognition on social function in schizophrenia spectrum disorders. Acta Psychiatr. Scand. 122, 405-13. doi:10.1111/j.1600-0447.2010.01554.x

Lysaker, P.H., Vohs, J., Minor, K.S., Irarrazaval, L., Leonhardt, B., Hamm, J.A., Kukla, M., Popolo, R., Luther, L., Buck, K.D., Wasmuth, S., Dimaggio, G., 2015. Metacognitive Deficits in Schizophrenia: Presence and Associations With Psychosocial Outcomes. J. Nerv. Ment. Dis. 203, 530-536. doi:10.1097

Meins, E., Fernyhough, C., Wainwright, R., Das Gupta, M., Fradley, E., Tuckey, M., 2002. Maternal mind-mindedness and attachment security as predictors of theory of mind understanding. Child Dev. 73, 1715-26.

Melle, I., Johannesen, J.O., Friis, S., Haahr, U.H., Joa, I., Larsen, T.K., Opjordsmoen, S., Rund, B.R., Simonsen, E., Vaglum, P., McGlashan, T., 2006. Early detection of the first episode of schizophrenia and suicidal behavior. Am. J. Psychiatry 163, 800-4. doi:10.1176/appi.ajp.163.5.800

Onwumere, J., Kuipers, E., Bebbington, P., Dunn, G., Freeman, D., Fowler, D., Garety, P., 2011. Coping styles in carers of people with recent and long-term psychosis. J. Nerv. Ment. Dis. 199, 423-4. doi:10.1097/NMD.0b013e31821ccb07

Scazufca, M., Kuipers, E., 1997. Impact on women who care for those with schizophrenia. Psychiatr. Bull. 21, 469-471. doi:10.1192/pb.21.8.469

Semerari, A., Carcione, A., Dimaggio, G., Falcone, M., Nicolo, G., Procacci, M., Alleva, G., 2003. How to evaluate metacognitive functioning in psychotherapy? The metacognition assessment scale and its applications. Clin. Psychol. Psychother. 10, 238-261. doi:10.1002/cpp.362

Sin, J., Moone, N., Newell, J., 2007. Developing services for the carers of young adults with early-onset psychosis - implementing evidence-based practice on psycho-educational family intervention. J. Psychiatr. Ment. Health Nurs. 14, 282-90. doi:10.1111/j.13652850.2007.01075.x 
Snethen, G. a, McCormick, B.P., Lysaker, P.H., 2014. Physical Activity and Psychiatric Symptoms in Adults With Schizophrenia Spectrum Disorders. J. Nerv. Ment. Dis. 202, 1-8. doi:10.1097/NMD.0000000000000216

Szmukler, G.I., Burgess, P., Herrman, H., Benson, A., Colusa, S., Bloch, S., 1996. Caring for relatives with serious mental illness: the development of the Experience of Caregiving Inventory. Soc. Psychiatry Psychiatr. Epidemiol. 31, 137-48. doi:10.1007/BF00785760

Tennakoon, L., Fannon, D., Doku, V., O’Ceallaigh, S., Soni, W., Santamaria, M., Kuipers, E., Sharma, T., 2000. Experience of caregiving: relatives of people experiencing a first episode of psychosis. Br. J. Psychiatry, Journal of Mental Science 177, 529-33. doi:10.1192/bjp.177.6.529

Trauelsen, A.M., Gumley, A., Jansen, J.E., Pedersen, M.B., Nielsen, H.-G.L., Trier, C.H., Haahr, U.H., Simonsen, E., 2016. Metacognition in first-episode psychosis and its association with positive and negative symptom profiles. Psychiatry Res. 238, 14-23. doi:10.1016/j.psychres.2016.02.003

Wearden, A.J., Tarrier, N., Barrowclough, C., Zastowny, T.R., Rahill, A.A., 2000. A review of expressed emotion research in health care. Clin. Psychol. Rev. 20, 633-666. doi:10.1016/S0272-7358(99)00008-2

Wiedemann, G., Rayki, O., Feinstein, E., Hahlweg, K., 2002. The Family Questionnaire: Development and validation of a new self-report scale for assessing expressed emotion. Psychiatry Res. 109, 265-279. doi:10.1016/S0165-1781(02)00023-9

Table 1 Means and standard deviations for study measures $(n=28)$.

\begin{tabular}{|c|c|c|c|c|}
\hline Variables & M & SD & $\begin{array}{l}\text { Observed } \\
\text { Range }\end{array}$ & $\begin{array}{l}\text { Possible } \\
\text { Range }\end{array}$ \\
\hline \multicolumn{5}{|l|}{ Patient } \\
\hline MAS-A - Mastery: Patient & 4.39 & 1.40 & $1-7$ & $0-9$ \\
\hline DUP in weeks ${ }^{c}$ & 109.54 & 171.43 & $2-832$ & \\
\hline PANSS - Negative symptoms & 15.75 & 5.56 & $8-27$ & $8-56$ \\
\hline \multicolumn{5}{|l|}{ Caregiver } \\
\hline PANSS - Positive symptoms & 12.54 & 5.32 & $6-22$ & $6-42$ \\
\hline MAS-A - Mastery: Mother & 6.13 & 1.87 & $2-8.5$ & $0-9$ \\
\hline ECI - Positive caregiver experiences & 29.04 & 9.12 & $7-46$ & $0-56$ \\
\hline ECI - Negative caregiver experiences & 75.32 & 29.27 & $12-129$ & $0-208$ \\
\hline FQ - Caregiver critical comments & 18.36 & 4.71 & $10-30$ & $10-40$ \\
\hline $\begin{array}{l}\mathrm{FQ}-\text { Caregiver emotional } \\
\text { overinvolvement }\end{array}$ & 24.32 & 5.22 & $16-36$ & $10-40$ \\
\hline \multicolumn{5}{|l|}{ Combined } \\
\hline MAS-A - Average dyad Mastery ${ }^{\mathrm{a}}$ & 5.26 & 1.38 & $1.75-7$ & $0-9$ \\
\hline $\begin{array}{l}\text { MAS-A - Absolute difference dyad } \\
\text { Mastery }\end{array}$ & 2.09 & 1.36 & $0-5$ & $0-9$ \\
\hline
\end{tabular}


${ }^{\mathrm{a}}$ Average of mother and patient mastery; ${ }^{\mathrm{b}}$ Absolute difference between mother and patient mastery; ${ }^{\mathrm{c}}$ Four missing.

Note: MAS-A = Metacognition Assessment Scale Abbreviated; DUP = Duration of untreated psychosis; ECI = Experience of Caregiving Inventory; FQ = Family Questionnaire; PANSS = Positive and Negative Syndrome Scale.

Table 2 Partial correlations between mastery and study measures among mother and patient dyads, controlling for patient negative symptoms $(n=28)$

\begin{tabular}{|c|c|c|c|c|}
\hline Variable & $\begin{array}{l}\text { Patient } \\
\text { Mastery }\end{array}$ & $\begin{array}{l}\text { Mother } \\
\text { Mastery }\end{array}$ & $\begin{array}{l}\text { Average } \\
\text { Dyad } \\
\text { Mastery }^{\mathrm{a}}\end{array}$ & $\begin{array}{l}\text { Absolute } \\
\text { Difference } \\
\text { Dyad } \\
\text { Mastery }\end{array}$ \\
\hline DUP in weeks ${ }^{\mathrm{c}}$ & -.18 & $-.43 *$ & $-.36^{*}$ & $-.34^{\mathrm{t}}$ \\
\hline ECI - Positive caregiver experiences & .01 & $.26^{\mathrm{t}}$ & .19 & -.09 \\
\hline ECI - Negative caregiver experiences & $-.54 * *$ & $-.26^{\mathrm{t}}$ & $-.45^{*}$ & .24 \\
\hline FQ - Caregiver critical comments & $-.45 * *$ & $-.33 *$ & $-.45 * *$ & .10 \\
\hline $\begin{array}{l}\text { FQ - Caregiver emotional } \\
\text { overinvolvement }\end{array}$ & $-.31^{\mathrm{t}}$ & .02 & -.13 & $.40^{*}$ \\
\hline
\end{tabular}

${ }^{\mathrm{a}}$ Average of mother and patient mastery; ${ }^{\mathrm{b}}$ Absolute difference between mother and patient mastery; ${ }^{\mathrm{c}}$ Four missing.

Note: DUP = Duration of untreated psychosis; $\mathrm{ECI}=$ Experience of Caregiving Inventory; $\mathrm{FQ}=$ Family Questionnaire.

${ }^{\mathrm{t}} p<.10 ; * p<.05 . ; * *<.01$

\section{Highlights}

- First study to examine metacognitive mastery in both caregivers and persons with psychosis

- Clinical implications in terms of improved understanding of caregiving relationships and help seeking behaviour 